\title{
The Economic Burden of Obesity in Germany: Results from the Population- Based KORA Studies
}

\author{
Nichola Yates ${ }^{a} \quad$ Christina M. Teuner ${ }^{a}$ Matthias Hunger ${ }^{a}$ Rolf Holle $e^{a} b$ \\ Renée Stark $^{a}$ Michael Laxy ${ }^{a, b}$ Hans Hauner ${ }^{c} \quad$ Annette Peters ${ }^{b} d$ \\ Silke B. Wolfenstetter ${ }^{a}$ \\ ${ }^{a}$ Institute of Health Economics and Health Care Management, German Research Centre \\ for Environmental Health, Helmholtz Zentrum München, Neuherberg, Germany; ${ }^{b}$ German \\ Centre for Diabetes Research, Neuherberg, Germany; ' Institute for Nutritional Medicine, \\ Klinikum rechts der Isar, Technische Universität München, Munich, Germany; Institute of \\ Epidemiology II, German Research Centre for Environmental Health, Helmholtz Zentrum \\ München, Neuherberg, Germany
}

\author{
Key Words \\ Obesity · Overweight · Excess costs · Bottom-up approach · Germany
}

\begin{abstract}
Objective: To estimate the excess costs of obese compared to normal-weight persons in Germany based on self-reported resource utilisation and work absence. Methods: Five cross sectional surveys of cohort studies in southern Germany were pooled resulting in 9,070 observations for 6,731 individuals (31-96 years). BMI was measured in the study centre. Self-reported health care utilisation and work absence was used to estimate direct and indirect costs for the year 2011 based on unit costs. Using regression analyses, adjusted costs for different BMI groups were calculated. Results: Overweight and obese people showed significantly higher odds of health care utilisation and productivity losses compared with normal-weight people in most categories. Total direct/indirect costs were significantly higher with increasing severity of obesity (pre-obese $(1.05(0.90-1.23) / 1.38(1.11-1.71))$, obesity level I (1.18 (1.00-1.39) / 1.33 (1.02-1.73)), obesity level II (1.46 (1.14-1.87) / 1.77 (1.18-2.65)) or level III (2.04 (1.40$2.97)$ / 1.99 (1.20-3.30)) compared to normal-weight participants. In particular, higher obesity classes were significantly associated with increased costs for medication, general practitioner
\end{abstract}

Nichala Yates and Christina M. Teuner contributed equally to this manuscript. 
Yates et al.: The Economic Burden of Obesity in Germany: Results from the PopulationBased KORA Studies

utilisation and work absence. Conclusion: Our results show that overweight and obesity are associated with enormous societal direct and indirect costs in Germany. This supports the evidence from previous top-down studies, but provides important new information based on a large pooled data set and measured BMI.

(C) 2016 The Author(s)

Published by S. Karger GmbH, Freiburg

\section{Introduction}

Obesity is a worldwide health epidemic. Recently reported prevalence estimates for adult obesity (BMI $\geq 30 \mathrm{~kg} / \mathrm{m}^{2}$ ) have been as high as $33.9 \%$ in the USA and $21 \%$ in Western Europe [1]. In a worldwide comparison study based on a mix of self-reported and measured BMI values, Germany was ranked eighth regarding the prevalence of obesity [1]. In Germany, almost one-quarter of adult women (23.3\%) and adult men (23.9\%) are obese [2]. The proportion of the population that is overweight $\left(25 \mathrm{~kg} / \mathrm{m}^{2} \geq \mathrm{BMI}<30 \mathrm{~kg} / \mathrm{m}^{2}\right)$ is even higher, being $43.8 \%$ and $29.0 \%$ for men and women, respectively [2]. Despite the alarming level, the prevalence of obesity in Germany will likely increase, having risen by 1.4 and 4.4 percentage points for women and men, respectively, in the last decade alone [2]. The high prevalence of obesity is a concern due to various medical consequences $[3,4]$, including increased mortality [5] and their associated costs. These costs are incurred by increased utilisation of medical services [6,7], and by increased sick leave / absenteeism [8], early disability-linked retirement [9] and presenteeism [10].

Several earlier studies have examined the costs of obesity. Some studies have used population-attributable fractions (PAFs) to calculate costs based on aggregated data [11-15], a so-called top-down approach. However, PAFs are difficult to determine for obesity and are often based on different populations [16]. An alternative is to compare the costs of persons with obesity to those without obesity, thus estimating excess costs based on individual data (bottom-up approach). A review of cost analyses in European countries [17] showed that most of these earlier studies do not differentiate between obesity classes, mostly due to small sample sizes in the higher BMI categories.

The KORA project in southern Germany includes several population-based cohorts [18]. Using BMI measured in the study centre and patient-reported health care utilisation, studies in 2005 and 1999 [19-21] assessed excess costs of obesity with a bottom-up approach. While these studies found substantial costs associated with obesity, they examined only costs in individual cohorts at one time point and mostly focused on single cost components. Furthermore, small sample sizes were a problem for the higher obesity classes. Thus, an updated evaluation of population-based obesity costs in Germany based on a pooled sample of different surveys would strongly contribute to the existing literature.

Therefore, the aim of this study was to assess the difference in direct and indirect costs between pre-obese, obesity class I, obesity class II and obesity class III compared to normalweight individuals from a societal perspective. In order to examine direct medical costs and indirect costs according to obesity classes, the data of five cohort surveys were pooled to attain a high number of participants in each BMI category which provides robust results even in the class of BMI $\geq 40 \mathrm{~kg} / \mathrm{m}^{2}$. 
Yates et al.: The Economic Burden of Obesity in Germany: Results from the PopulationBased KORA Studies

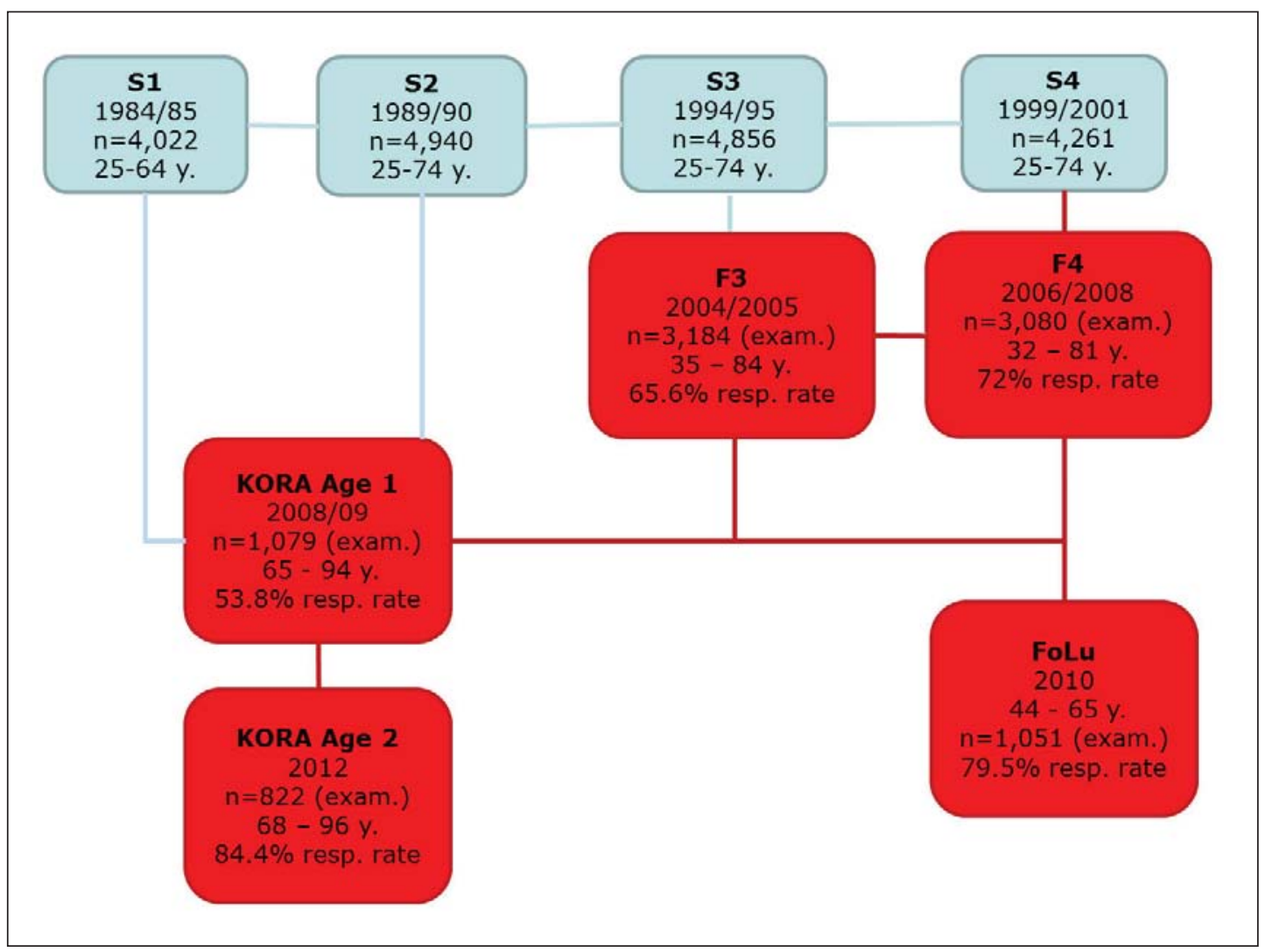

Fig. 1. Relationship between KORA studies.

\section{Material and Methods}

\section{Data and Study Design}

Data from five cohort surveys of the KORA project (Cooperative Health Research in the Augsburg Region) were pooled. These surveys were performed in 2004 to 2005 (F3), 2006 to 2008 (F4), 2008 to 2009 (Age 1), 2010 (FoLu) and 2012 (Age 2). They were follow-up surveys of four baseline surveys (fig. 1). The KORA project has been described in detail elsewhere [18]. Briefly, KORA is a research platform/programme for population-based cohort studies. All participants of KORA are of German nationality and have been selected from Augsburg, a city in the south-west of Germany, and two surrounding districts.

Collectively, the five studies have a sample size of $n=9,216$ observations (F3 n=3,184, F4 $n=3,080$, Age $1 \mathrm{n}=1,079$, Age $2 \mathrm{n}=822$ and FoLu $n=1,051)$. Most participants $(\mathrm{n}=4,869)$ took part in only one of the follow-up studies, 1,578 in two studies and 397 in three of the studies.

For all studies, participants came to the study centre and were interviewed regarding demographic and disease-related parameters, health care utilisation and medications. Thus, information on gender, age, education and BMI was available for all studies. Anthropometric (weight and height) measurements were performed by trained staff. Individuals with missing information for BMI were excluded from the analysis ( $\mathrm{n}=87$ ) as were subjects who were classified as underweight (BMI $\left.<18.5 \mathrm{~kg} / \mathrm{m}^{2}, \mathrm{n}=34\right)$. Participants were classified as normal weight $\left(18.5 \mathrm{~kg} / \mathrm{m}^{2} \leq \mathrm{BMI}<25 \mathrm{~kg} / \mathrm{m}^{2}\right)$ pre-obese $\left(25 \mathrm{~kg} / \mathrm{m}^{2} \leq \mathrm{BMI}<30 \mathrm{~kg} / \mathrm{m}^{2}\right)$, obesity level I ( $\left.30 \mathrm{~kg} / \mathrm{m}^{2} \leq \mathrm{BMI}<35 \mathrm{~kg} / \mathrm{m}^{2}\right)$, obesity level II $\left(35 \mathrm{~kg} / \mathrm{m}^{2} \leq \mathrm{BMI}<40 \mathrm{~kg} / \mathrm{m}^{2}\right)$ or level III (BMI $\geq 40 \mathrm{~kg} /$ $\mathrm{m}^{2}$ ) according to the World Health Organisation (WHO) definitions [17]. Education was classified in 3 groups: 'basic education' ( $\leq 9$ years of schooling), 'medium education' and 'higher education' ( $\geq 12$ years of schooling, which is required to enter university). Individuals with missing information on education were excluded from the analysis $(n=19)$. Income was classified in 5 groups - ' $<60 \%$ of the sample median', ' $>60 \%$ of the 
Yates et al.: The Economic Burden of Obesity in Germany: Results from the PopulationBased KORA Studies

median and $<$ sample median', ' $\geq$ sample median and $<150 \%$ of the median', ' $\geq 150 \%$ of the median' - or as 'unknown' ( $\mathrm{N}=654$ individuals).

Information on the health service usage of participants was also collected in all studies. Resource utilisation regarding physician visits, in- and out-patient hospital treatments and rehabilitations were assessed for a specific time period ( 3 or 12 months), prescription medication was assessed for the previous week. We extrapolated all measures of health care utilisation that were provided for a shorter period than 12 months to 1 year, under the assumption that the data were representative of the entire year.

In some of the studies, particular information was not given. In Age 1 and Age 2 information on rehabilitation and on out-patient hospital visits was not collected. For the estimation of total direct medical costs, these data were imputed using regression-based imputation methods. Finally, missing information on income and incapacity benefits in the FoLu survey (2011) was transferred from F4 (2008) as all participants in FoLu were also part of F4.

The plausibility of information on health service use was checked thoroughly. Five individuals who were considered to have provided implausible answers (e.g., having had 416 physician visits in the past year) were excluded from the analysis. One individual was excluded from the dataset due to extreme medication costs in excess of EUR 200,000. This resulted in a final sample size of $n=9,070$ observations, containing 6,731 individuals aged 31-96 years.

The economic burden of obesity was analysed from a societal perspective which includes costs of direct health care utilisation as well as costs due to productivity loss for the year 2011.

\section{Direct Costs}

Total direct medical costs included physician visits, in-patient hospital stays, out-patient hospital visits, in-patient rehabilitation, out-patient rehabilitation and medication.

The mean direct costs per contact with various medical practitioners, for rehabilitation and for in- and out-patient hospital stays are based on Bock et al. [22]. Contact values ranged from EUR 18.89 for a general practitioner appointment to EUR 78.08 for a psychotherapist appointment. For each individual, the 12-month costs for contacts with medical practitioners were calculated by multiplying the reported number of visits in the past 12 months by the average contact costs for each specialist group. For ease of analysis and due to the small number of visits to some specialist doctors, individual physician categories were then grouped together into: 'General Practitioners' (including general practitioners and specialists in internal medicine working as general practitioners), 'Internists' (including specialists in internal medicine, cardiology and pneumology) and 'Other Doctors' (including gynaecologists, surgeons, orthopaedists, urologists, ear nose and throat doctors, ophthalmologists, dermatologists, neurologists, psychotherapists/psychiatrists, company doctors, radiologists and other doctors). Total individual costs for the three categories described above were estimated.

The reasons for hospitalisation were not given. Per capita hospitalisation costs were therefore measured using an average daily price from Bock et al. [22], EUR 40.06 per out-patient visit and EUR 593.04 per in-patient day. In- and out-patient rehabilitation was priced at EUR 121.85 and EUR 46.68 per day, respectively, as suggested by Bock et al. [22].

The utilisation of prescription medications was assessed based on patient information on medication name, medication usage in the past week and national drug codes. The cost of medication was estimated using the pharmacy retail prices from the Scientific Institute of the AOK health care insurance (WIdO) [23]. Weekly costs were then extrapolated to 1 year and adjusted to 2011 prices using the price index calculator of the Federal Statistical Office [24]. Neither mandatory manufacturer discounts nor over the counter medications were taken into account.

\section{Indirect Costs}

The Institute for Quality and Efficiency in Health Care (IQWIG) describes indirect costs as the costs that are incurred due to productivity losses [25]. This includes reduced productivity, sick leave days, early retirement / long-term incapacity and premature death. In the KORA studies individuals under 65 years of age were asked whether they receive incapacity benefit, and those who were in regular full time or part time employment were asked how many days in the past year they were unable to go to work due to illness. In the main analysis, potential productivity losses were estimated based on the human capital approach as suggested by Krauth et al. [26].

The average annual income in Germany in 2011 was EUR 36,103 [27]. Assuming 211.3 effective work days [28], this results in a cost of 170.86 EUR/day of absence. Individuals who stated having been absent from work for greater than 211.3 days were restricted to 211.3 days of absenteeism $(n=10)$. 
Yates et al.: The Economic Burden of Obesity in Germany: Results from the PopulationBased KORA Studies

Given the scope of the KORA studies, it was not possible to consider other indirect costs such as premature death and presenteeism.

\section{Statistical Analyses}

To account for correlations between the data of participants with follow-up observations in the study sample, a Generalized Estimating Equations (GEE) approach was applied. Logistic regression models were fitted to examine the odds for different BMI categories that individuals use health services and have sick leave days (yes/no).

Secondly, health service and work absence costs for each BMI group were examined. Costs showed a highly skewed distribution, with a high number of individuals incurring zero costs, whilst a small number exhibited extremely high costs. To account for the skewed distribution, individuals with zero costs were given a cost of EUR 1.00 and GEE gamma models with a log-link were fitted. Analogously the effect of BMI on total direct and indirect costs was modelled. We report the adjusted mean costs in EUR for the normal-weight group (reference group) as well as exponents of regression estimates which represent factors by which the other groups differ from the normal-weight group.

All regression models were adjusted for age, age $^{2}$, gender, education level and income. Statistical analyses were performed using the statistical software SAS (SAS Institute Inc., Cary, NC, USA; Version 9.3).

\section{Sensitivity Analyses}

Due to the irregular administration of some medications and uncertainty around dosage for certain individuals, a sensitivity analysis was performed using Defined Daily Dose (DDD) values in place of patient stated medication dosages. DDD is the defined average maintenance dose per day for a drug when it is used for its main indication in adults [29]. These values were then multiplied by medication costs from the WidO [23] and extrapolated to be representative for a year.

To enable GEE gamma models to be fitted, individuals with zero costs were given a hypothetical value of EUR 1.00. To examine the effect of applying a negligible positive cost, individuals with zero costs were attributed costs of EUR 0.50 and then EUR 5.00.

A further sensitivity analysis was conducted to examine the effect of using the friction cost approach as opposed to the human capital approach, as suggested by Krauth et al. [26, 30]. In Germany in 2011 the average friction period (the length of time to find a new employee) was 76 calendar days, equivalent to 52 business days [31,32]. When the sick leave of a worker is shorter than the friction period, the productivity loss is assumed to be $80 \%$ of the value of productivity as some of their tasks can be performed by other members of staff. After the friction period, there is no productivity loss attributable to the individual as a new member of staff is responsible for their workload.

\section{Results}

\section{Sample Description}

Table 1 presents the socio-demographic characteristics of the baseline population (defined as the earliest observation set for each participant). Of the baseline participants, around 30\% were normal-weight, $43 \%$ were pre-obese, $20 \%$ were categorised as obese level I whilst $5 \%$ and $2 \%$ were categorised as obese level II and obese level III, respectively.

\section{Regression Analyses}

Table 2 shows the odds of using different health care services and taking sick leave from work, dependent on BMI category. Overweight and obese individuals showed significantly higher odds of visiting a general practitioner and taking medication. Indeed, the odds to take prescription medication for individuals with a BMI $\geq 40 \mathrm{~kg} / \mathrm{m}^{2}$ (level III) were more than fivefold compared to normal-weight individuals. Other cost categories, such as in-patient hospital treatment or work sick days, were significantly elevated only for the higher obesity classes.

The costs associated with health care use and sick leave for the different BMI groups are summarised in table 3. Compared to those considered normal-weight (adjusted mean general 
Yates et al.: The Economic Burden of Obesity in Germany: Results from the PopulationBased KORA Studies

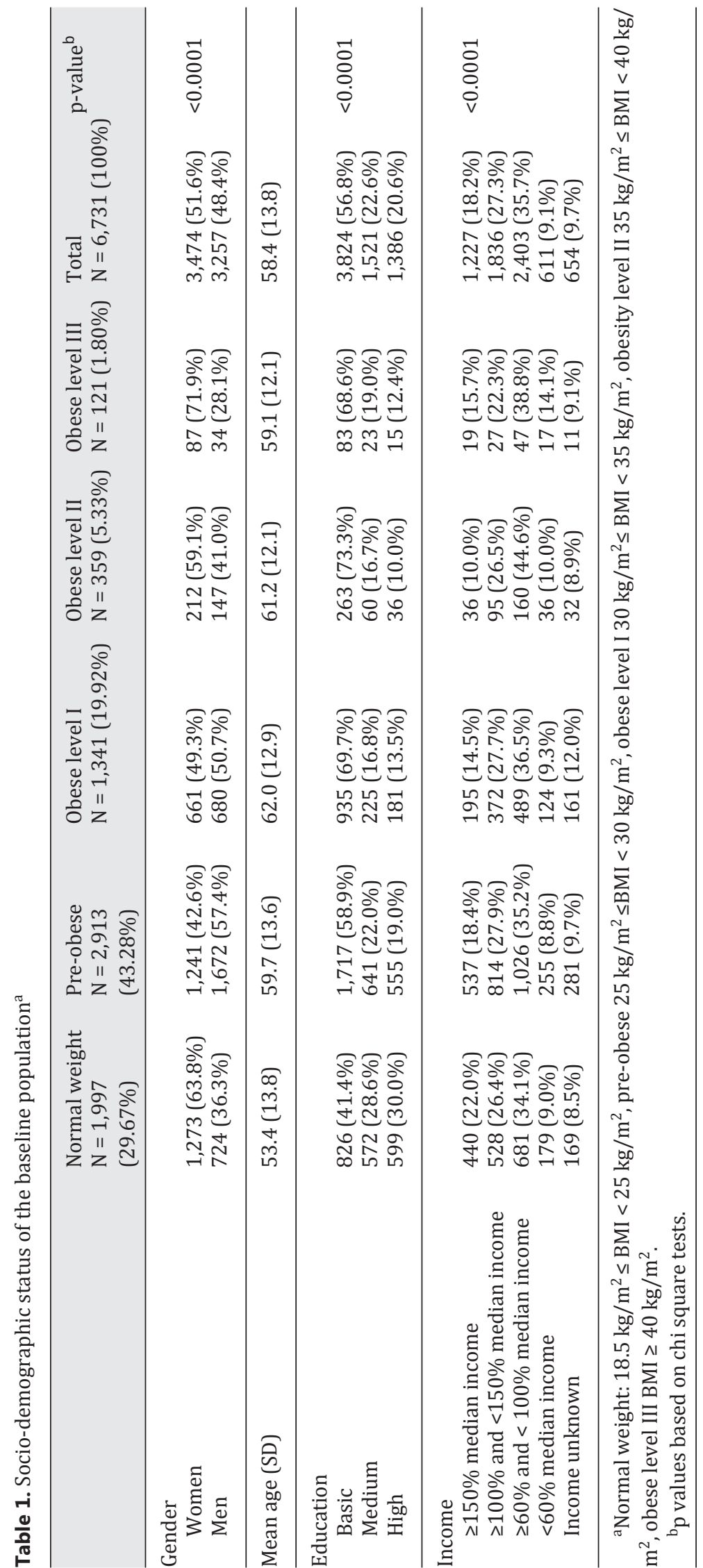




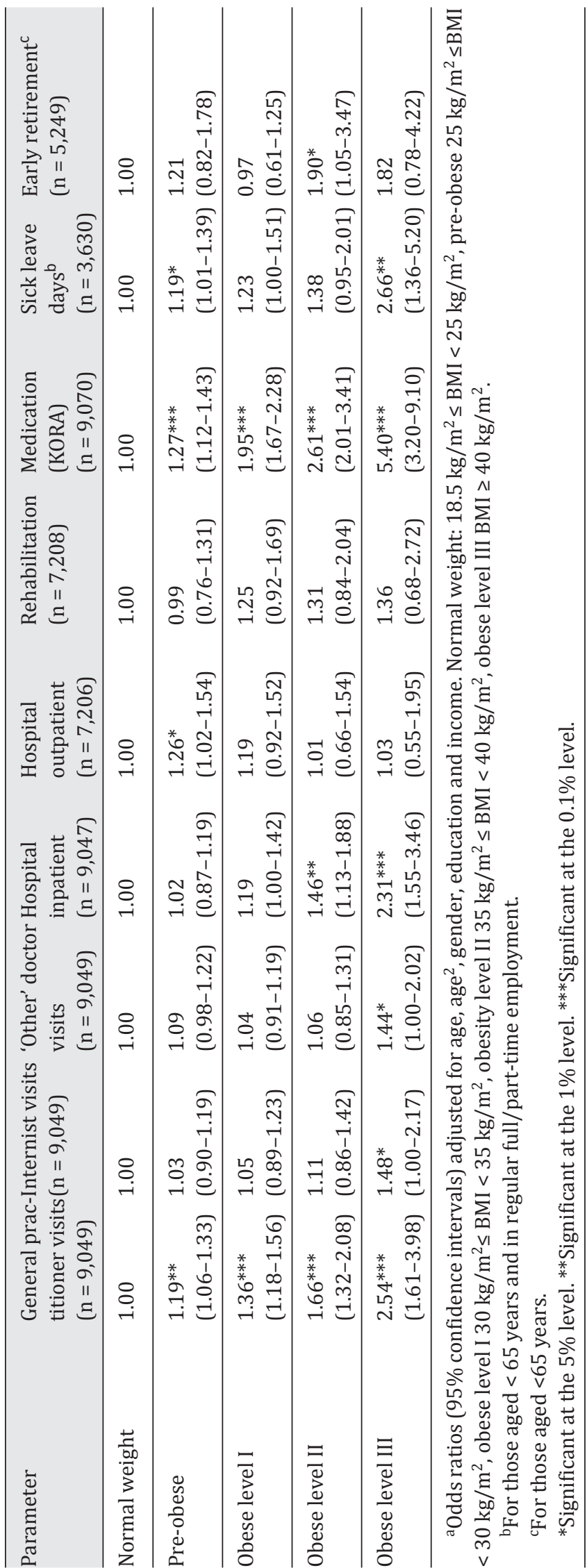

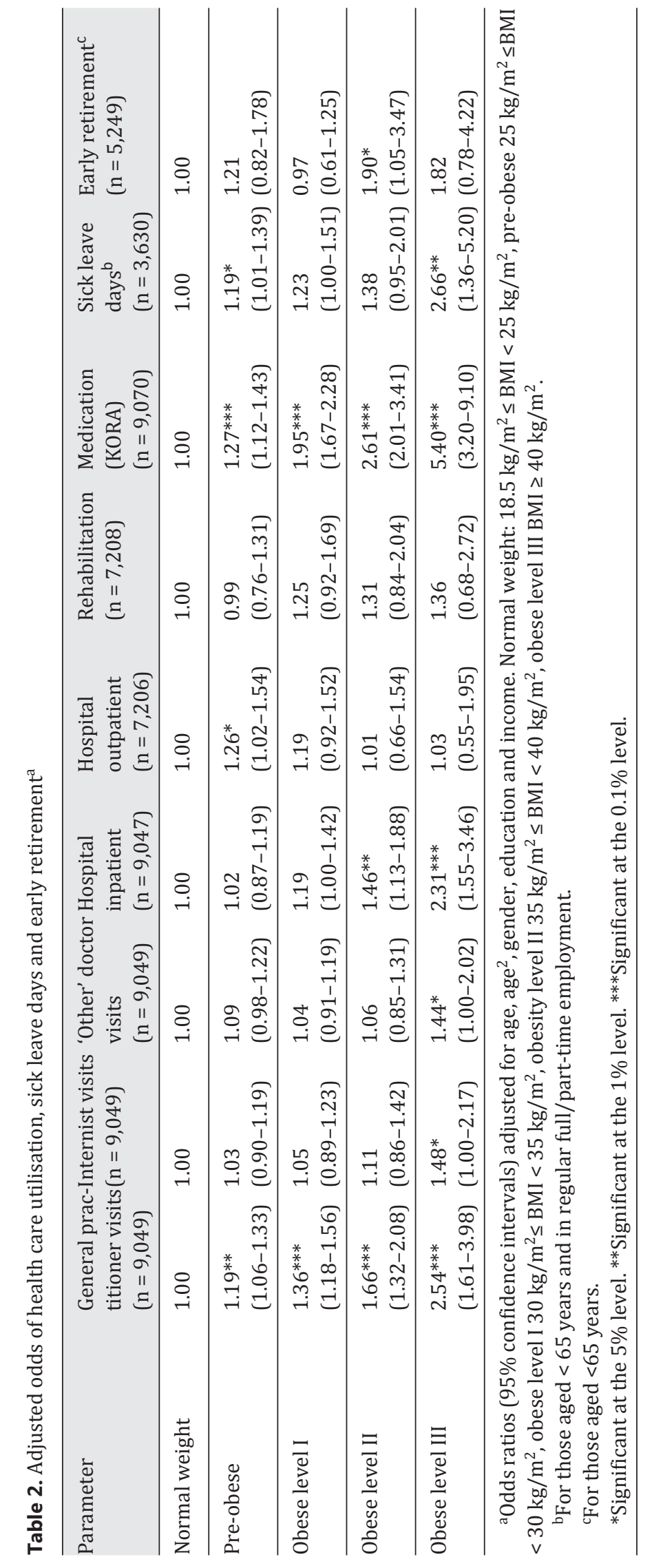


Yates et al.: The Economic Burden of Obesity in Germany: Results from the PopulationBased KORA Studies

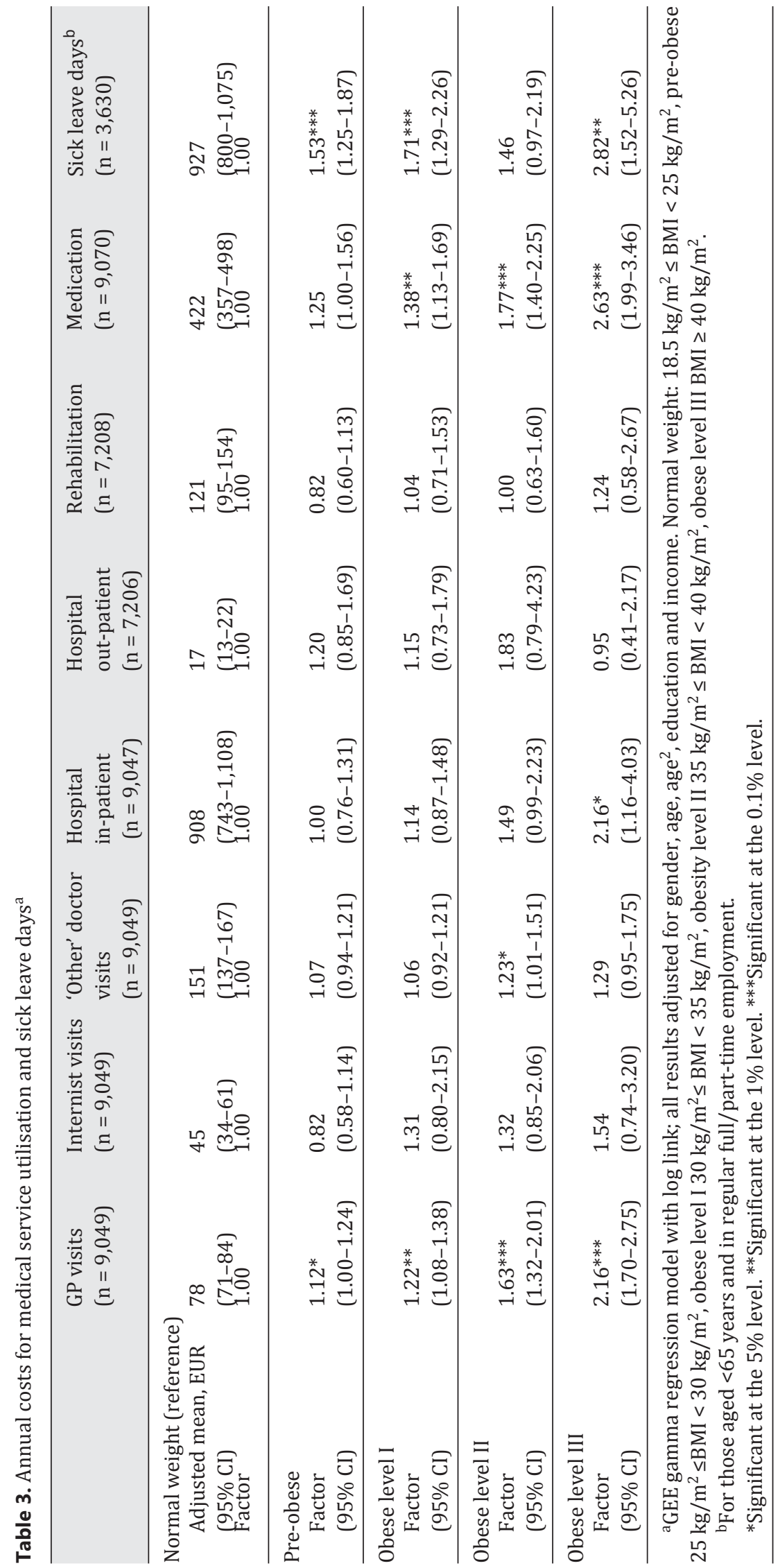


Yates et al.: The Economic Burden of Obesity in Germany: Results from the PopulationBased KORA Studies

Table 4. Overall annual direct and indirect $\operatorname{costs}^{\mathrm{a}}$

\begin{tabular}{|c|c|c|}
\hline Weight status & $\begin{array}{l}\text { Direct medical costs } \\
N=9,043(95 \% \mathrm{CI})\end{array}$ & $\begin{array}{l}\text { Indirect costs }^{\mathrm{b}} \\
\mathrm{N}=5,250(95 \% \mathrm{CI})\end{array}$ \\
\hline \multicolumn{3}{|l|}{ Normal weight (reference) } \\
\hline Adjusted mean, EUR & $1,785(1,581-2,014)$ & $1,535(1,292-1,825)$ \\
\hline Factor & 1.00 & 1.00 \\
\hline \multicolumn{3}{|l|}{ Pre-obese } \\
\hline Factor & $1.05(0.90-1.23)$ & $1.38^{* *}(1.11-1.71)$ \\
\hline \multicolumn{3}{|l|}{ Obese level I } \\
\hline Factor & $1.18^{*}(1.00-1.39)$ & $1.33^{*}(1.02-1.73)$ \\
\hline \multicolumn{3}{|l|}{ Obese level II } \\
\hline Factor & $1.46^{* *}(1.14-1.87)$ & $1.77^{* *}(1.18-2.65)$ \\
\hline \multicolumn{3}{|l|}{ Obese level III } \\
\hline Factor & $2.04^{* * *}(1.40-2.97)$ & $1.99 * *(1.20-3.30)$ \\
\hline \multicolumn{3}{|c|}{$\begin{array}{l}{ }^{\mathrm{a}} \mathrm{GEE} \text { gamma regression model with log link; all results adjusted for gender, age, age }{ }^{2} \text {, education and } \\
\text { income. Normal weight: } 18.5 \mathrm{~kg} / \mathrm{m}^{2} \leq \mathrm{BMI}<25 \mathrm{~kg} / \mathrm{m}^{2} \text {, pre-obese } 25 \mathrm{~kg} / \mathrm{m}^{2} \leq \mathrm{BMI}<30 \mathrm{~kg} / \mathrm{m}^{2} \text {, obese level I } \\
30 \mathrm{~kg} / \mathrm{m}^{2} \leq \mathrm{BMI}<35 \mathrm{~kg} / \mathrm{m}^{2} \text {, obesity level II } 35 \mathrm{~kg} / \mathrm{m}^{2} \leq \mathrm{BMI}<40 \mathrm{~kg} / \mathrm{m}^{2} \text {, obese level III BMI } \geq 40 \mathrm{~kg} / \mathrm{m}^{2} \text {. } \\
\text { bFor those aged }<65 \text { years. } \\
{ }^{*} \text { Significant at the } 5 \% \text { level. }{ }^{* *} \text { Significant at the } 1 \% \text { level. }{ }^{* *} \text { Significant at the } 0.1 \% \text { level. }\end{array}$} \\
\hline
\end{tabular}

practitioner costs of about EUR 78), the general practitioner costs of individuals classified as obese level II and obese level III were 63\% (adjusted mean costs EUR 126) and 116\% (adjusted mean costs EUR 168) higher, respectively. A similar trend was seen for medication and sick leave days.

Table 4 shows the effect of BMI on overall annual direct and indirect costs. Total annual direct medical costs were significantly higher for the obese groups compared to the normalweight group. Moreover, costs increased with increasing BMI group. Having a BMI over 35 $\mathrm{kg} / \mathrm{m}^{2}$ or over $40 \mathrm{~kg} / \mathrm{m}^{2}$ increased total direct costs by $46 \%$ and $104 \%$, compared to the normal-weight group. Indirect costs (adjusted mean for normal weight EUR 1,535) were found to be significantly higher for the pre-obese group, but also for all obesity groups compared to the normal-weight group.

\section{Sensitivity Analyses}

Using DDD values in place of patient-stated medication dosages changed neither the costs for medication use nor the annual direct excess costs of overweight and obesity significantly. Also, attributing costs of EUR 0.50 or EUR 5.00 instead of EUR 1.00 for individuals with zero costs had no substantive effect on the regression coefficients or their significance. Using the friction cost approach as opposed to the human capital approach reduced the excess indirect costs by $20 \%$.

\section{Discussion}

Detailed knowledge about the costs of chronic diseases is needed for resource allocation and decision making in health care. This is the first large population-based bottom-up study in Germany to examine the effect of different obesity classes on health care utilisation, produc- 
Yates et al.: The Economic Burden of Obesity in Germany: Results from the PopulationBased KORA Studies

tivity loss and associated direct and indirect costs. For this we used pooled data from five population-based studies. Results showed that total direct medical costs were monotonously increasing with increasing BMI group, with a significant increase compared to the normalweight group for obese class I to III, but not for the pre-obese group. Looking at the single cost components, this is especially obvious regarding costs for general practitioner visits and medication. Indirect costs, in contrast, were significantly higher already for the pre-obese group of participants and increased further for obese class II and III participants.

Our results are similar to those of a European review of cost of illness studies that reported annual excess health care costs of obesity ranging between EUR 117 and EUR 1,873, mainly depending on analysed cost components and comparison groups [17]. Compared to normalweight participants, we calculated excess direct medical costs ranging from about EUR 300 for obesity level I to about EUR 800 for obesity level II and more than EUR 1,800 for obesity level III participants. Pre-obese participants incurred significantly higher indirect costs (especially work sick days), but regarding direct medical costs our results for this group were not as clear. Compared to the results of two German top-down studies [11,12], excess costs for direct and indirect cost components were similar in absolute terms.

A review of excess costs of obesity worldwide showed that obesity (BMI $\geq 30 \mathrm{~kg} / \mathrm{m}^{2}$ ) was associated with direct medical costs which were about $30 \%$ higher than for the non-obese population [33]. In the USA, incremental costs for obesity were calculated to be $42 \%$ higher than that of persons with normal weight [34]. Two earlier studies used the high sample size of the US Medical Expenditure Panel Survey (MEPS) to examine costs according to severity of obesity [35, 36]. Similar to the study by Wee et al. [36], Arterburn et al. [35] showed that direct medical costs of the groups overweight, obesity class I, obesity class II, and obesity class III were $10 \%, 23 \%, 45 \%$ and $81 \%$ higher, respectively, than those of the normal-weight group [35]. This is also similar to our results, which are less clear for the overweight group, but show $18 \%, 46 \%$ and $104 \%$ higher direct medical costs for the obesity classes I, II and III, respectively. However, both MEPS studies are based on self-reported weight and height, which is likely to cause underestimation of BMI and might explain part of the differences to our results, especially in the overweight group.

A review on indirect (non-medical) costs showed that obesity was associated with productivity losses due to short-term absenteeism and long-term disability. The relative risks for missed work due to disability varied between 1.15 and 2.8 for obese versus non-obese people [37].

Only a few studies have estimated the cost of overweight and obesity in Germany. To our knowledge, this is the first study using a bottom-up approach to estimate cross-sectional excess costs of obesity based on a pooled sample of more than 9,000 observations. The advantage of this study over top-down studies is that it does not rely on population-attributable fractions, which have to be derived from multiple different sources and depend on assumptions regarding the inclusion or exclusion of associated diseases. The bottom-up approach enabled consideration of all obesity-associated medical costs. The KORA studies also ensured that height and weight measurements of individuals in the sample were performed by specially trained staff. This is more accurate than self-reported measurements where people tend to under-estimate their weight and over-estimate their height, leading to an under-estimation in BMI [2]. Furthermore, a detailed analysis based on measured BMI data is not possible when analysing administrative statistics such as insurance claims data. In Germany, health insurance data does not contain BMI measurements, and physician ICD coding may be inconsistent and incomplete $[38,39]$. Thus, identification of obese patients or stratification by BMI class is difficult or impossible. In this respect, costs associated with obesity based on cohort studies with standardised height and weight measurements has an advantage. 
Yates et al.: The Economic Burden of Obesity in Germany: Results from the PopulationBased KORA Studies

However, our study was also subject to certain limitations. Only subjects with German nationality living in the region of Augsburg in southern Germany were included in the KORA studies [18]. Also, elderly people were over-represented in the sample, as the Age 1 and Age 2 study included only individuals aged $\geq 65$ years and $\geq 68$ years, respectively. Although age was included as confounder in our regression models, we cannot rule out residual confounding. As shown in figure 1, the KORA studies were all subject to non-response which may lead to selection bias. The possibility that intrinsic differences exist between individuals who never participated, those who participated once and those who participated in two or three of the studies can therefore not be ruled out. Also severely ill individuals might not be included in our study because of their inability to reach the study centre which might lead to underestimation of costs. As participants were asked to self-report their health service usage over the past 3-12 months, recall bias cannot be excluded. However, this should not influence the validity of the study results [40]. Health care utilisation was priced with an average reference value, which might deviate from the actual costs occurred. Moreover, we were not able to consider some cost categories such as presenteeism, premature death or out-of-pocket payments for medication. However, although the problem of recall bias and average unit costs are likely to lead to an underestimation of absolute costs, this should not influence the cost differences between BMI groups that were the focus of this study. Moreover, it should be noted that, especially for those cost components and BMI groups where a gamma distribution fits less well, adjusted mean costs tend to be underestimated. However, this also does not affect the estimated factors for BMI groups compared to the normal-weight group. Furthermore, it has to be noted that this study analyses the correlation of obesity and societal costs; causal effects cannot be stated based on our approach. Cawley and Meyerhoefer [41] presented an analysis of obesity-attributable costs based on an instrumental variables (IV) approach using data from the US MEPS. They conclude that the real impact of obesity on health care costs is significantly higher than estimates derived from pure correlation studies because of two main reasons: i) reporting error in weight and height is accounted for by their IV model and ii) omitted variables bias in correlation studies, e.g. when subgroups with higher obesity prevalence have reduced access to care. Based on our pooled KORA data set, a similar IV approach was not possible, but this finding by Cawley and Meyerhoefer [41] implies that our results are likely to underestimate the real medical costs of obesity. However, the underestimation should be much smaller than in their study. While the first reason for underestimation does not apply at all for KORA studies which offer measured BMI data, the second reason might well apply, but, given a social insurance system covering almost all citizens in Germany, this effect should be much smaller compared to the USA.

\section{Conclusions}

In conclusion, the results of this study provide further evidence of the increased costs associated with overweight and obesity in adults. Given the differences in design and parameter inclusion between this and previous studies, obesity cost estimates should be compared with caution. Germany's high prevalence of obesity [1], evidence from the DEGS1 study that the prevalence of obesity is increasing [2] and the increased health care costs especially for higher BMI groups presented in this study provide compelling evidence for the increasing importance of obesity and the need for more prevention and intervention programmes. 
Yates et al.: The Economic Burden of Obesity in Germany: Results from the PopulationBased KORA Studies

\section{Authors Contributions}

NY designed the concept for the paper, performed the statistical analysis and interpreted the data. $\mathrm{MH}$ and ML provided statistical support. NY, CT and RS drafted the manuscript. CT, RH, HH and SW were involved in the coordination of the study, co-designed the concept of the manuscript and commented on the manuscript. AP and RH were involved in collecting the data. All authors read and approved the final version of the manuscript.

\section{Acknowledgement}

This article was written as part of the Competence Network Obesity, supported under grant number 01 GI1127 by the German Federal Ministry of Education and Research.

\section{Disclosure Statement}

The authors have no conflict of interest with regard to this work, and there are no ethical considerations in connection to the datasets used.

\section{References}

$1 \mathrm{Ng} \mathrm{M}$, Fleming T, Robinson M, et al: Global, regional, and national prevalence of overweight and obesity in children and adults during 1980-2013: a systematic analysis for the global burden of disease study 2013. The Lancet 2014;384:766-781.

2 Mensink GB, Schienkiewitz A, Haftenberger M, Lampert T, Ziese T, Scheidt-Nave C: Overweight and obesity in Germany: results of the German health interview and examination survey for adults (DEGS1) (in German). Bundesgesundheitsbl Gesundheitsforsch Gesundheitsschutz 2013;56:786-794.

3 Centers for Disease Control and Prevention: Adult Overweight and Obesity. www.cdc.gov/obesity/adult/index. html (last accessed December 1, 2016).

4 Bray GA: Medical consequences of obesity. J Clin Endocrinol Metab 2004;89:2583-2589.

5 Schneider HJ, Friedrich N, Klotsche J, Pieper L, Nauck M, John U, Dorr M, Felix S, Lehnert H, Pittrow D, Silber S, Volzke H, Stalla GK, Wallaschofski H, Wittchen HU: The predictive value of different measures of obesity for incident cardiovascular events and mortality. J Clin Endocrinol Metab 2010;95:1777-1785.

6 Bertakis KD, Azari R: Obesity and the use of health care services. Obes Res 2005;13:372-379.

7 Hauner H, Koster I, von Ferber L: Frequency of 'obesity' in medical records and utilization of out-patient health care by 'obese' subjects in Germany. An analysis of health insurance data. Int J Obes Relat Metab Disord 1996; 20:820-824.

8 Lehnert T, Stuhldreher N, Streltchenia P, Riedel-Heller SG, Konig HH: Sick leave days and costs associated with overweight and obesity in Germany. J Occup Environ Med 2014;56:20-27.

9 Renna F, Thakur N: Direct and indirect effects of obesity on u.S. Labor market outcomes of older working age adults. Soc Sci Med 2010;71:405-413.

10 Gates DM, Succop P, Brehm BJ, Gillespie GL, Sommers BD: Obesity and presenteeism: the impact of body mass index on workplace productivity. J Occup Environ Med 2008;50:39-45.

11 Konnopka A, Bodemann M, Konig HH: Health burden and costs of obesity and overweight in Germany. Eur J Health Econ 2011;12:345-352.

12 Sander B, Bergemann R: Economic burden of obesity and its complications in Germany. Eur J Health Econ 2003; 4:248-253

13 Knoll KP, Hauner H: Kosten der Adipositas in der Bundesrepublik Deutschland - eine aktuelle Krankheitskostenstudie. Adipositas 2008;2:204-210.

14 Aitken RJ, Allman-Farinelli MA, King LA, Bauman AE: Current and future costs of cancer, heart disease and stroke attributable to obesity in Australia - a comparison of two birth cohorts. Asia Pac J Clin Nutr 2009;18: 63-70.

15 Lal A, Moodie M, Ashton T, Siahpush M, Swinburn B: Health care and lost productivity costs of overweight and obesity in New Zealand. Aust N Z J Public Health 2012;36:550-556.

16 Wirth A, Holle R, Teuner CM: Ökonomische Aspekte der Adipositas; in Wirth A, Hauner H (eds): Adipositas Ätiologe, Folgekrankheiten, Diagnostik, Therapie. Berlin, Springer, 2013, pp 41-43.

17 von Lengerke T, Krauth C: Economic costs of adult obesity: a review of recent European studies with a focus on subgroup-specific costs. Maturitas 2011;69:220-229. 
Yates et al.: The Economic Burden of Obesity in Germany: Results from the PopulationBased KORA Studies

18 Holle R, Happich M, Lowel H, Wichmann HE: KORA - a research platform for population based health research (in German). Gesundheitswesen 2005;67(suppl 1):S19-25.

19 Wolfenstetter SB: Future direct and indirect costs of obesity and the influence of gaining weight: Results from the MONICA/KORA cohort studies, 1995-2005. Econ Hum Biol 2012;10:127-138.

20 von Lengerke T, Reitmeir P, John J: Direct medical costs of (severe) obesity: a bottom-up assessment of overvs. normal-weight adults in the KORA-study region (Augsburg, Germany) (in German). Gesundheitswesen 2006;68:110-115.

21 Teuner CM, Menn P, Heier M, Holle R, John J, Wolfenstetter SB: Impact of BMI and BMI change on future drug expenditures in adults: Results from the MONICA/KORA cohort study. BMC Health Services Res 2013;13:424.

22 Bock JO, Brettschneider C, Seidl H, Bowles D, Holle R, Greiner W, König HH: Calculation of standardised unit costs from a societal perspective for health economic evaluation (in German). Gesundheitswesen 2015;77: 53-61.

23 Wissenschaftliches Institut der AOK (WIdO): Arzneimittel. 2014. www.wido.de/arzneimittel.html (last accessed November 30, 2016).

24 Statistisches Bundesamt: Verbraucherpreisindex: Deutschland, Monate, Klassifikation der Verwendungszwecke des Individualkonsums. Wiesbaden, 2014 www-genesis.destatis.de/genesis/online/logon?sequenz=tab elleErgebnis\&selectionname $=61111-0004 \&$ sachmerkmal $=$ CC98A4\&sachschluessel=CC06*zeitscheiben $=3$ (last accessed November 30, 2016).

25 Institut für Qualität und Wirtschaftlichkeit im Gesundheitswesen (IQWiG): Arbeitspapier Kostenbestimmung 2009, Version 1.0. www.iqwig.de/download/Arbeitspapier_Kostenbestimmung_v_1_0.pdf (last accessed November 30, 2016).

26 Krauth C, Hessel F, Hansmeier T, Wasem J, Seitz R, Schweikert B: Empirical standard costs for health economic evaluation in Germany - a proposal by the working group methods in health economic evaluation (in German). Gesundheitswesen 2005;67:736-746.

27 Statistisches Bundesamt: VGR der Länder - Arbeitnehmerentgelt, Bruttolöhne und -Gehälter in den Ländern der Bundesrepublik Deutschland 2000 bis 2014. Reihe 1, band 2. Stuttgart, 2015. /www.Destatis.De/de/ publikationen/thematisch/volkswirtschaftlichegesamtrechnungen/vgrderlaender/vgr_laenderergebnisseband2.html. (last accessed November 30, 2016).

28 Fuchs J HM, Hutter C, Klinger S, Wanger S, Weber E, Weigand R, Zika G: Arbeitsmarkt 2014/2015. Robust, aber risikobehaftet. http://doku.Iab.De/kurzber/2014/kb1814.Pdf (last accessed November 30, 2016).

29 WHO Collaborating Centre for Drug Statistics Methodology: Definition and general considerations 2016. www. whocc.no/ddd/definition_and_general_considera/(last accessed November 30, 2016).

30 Koopmanschap MA, Rutten FF, van Ineveld BM, van Roijen L: The friction cost method for measuring indirect costs of disease. J Health Econ 1995;14:171-189.

31 Institut für Arbeitsmarkt- und Berufsforschung (IAB): Arbeitslosigkeit sinkt trotz Beschäftigungsrekord nur wenig. http://doku.iab.de/kurzber/2013/kb1813.pdf (last accessed November 30, 2016).

32 Institut für Arbeitsmarkt- und Berufsforschung (IAB): Strukturwandel und Demografie prägten die Personalsuche. www.iab.de/194/section.aspx/Publikation/k130819303 (last accessed November 30, 2016).

33 Withrow D, Alter DA: The economic burden of obesity worldwide: a systematic review of the direct costs of obesity. Obes Rev 2011;12:131-141.

34 Tsai AG, Williamson DF, Glick HA: Direct medical cost of overweight and obesity in the USA: A quantitative systematic review. Obes Rev 2011;12:50-61.

35 Arterburn DE, Maciejewski ML, Tsevat J: Impact of morbid obesity on medical expenditures in adults. Int J Obes 2005;29:334-339.

36 Wee CC, Phillips RS, Legedza AT, Davis RB, Soukup JR, Colditz GA, Hamel MB: Health care expenditures associated with overweight and obesity among us adults: Importance of age and race. Am J Public Health 2005;95: 159-165.

37 Trogdon JG, Finkelstein EA, Hylands T, Dellea PS, Kamal-Bahl SJ: Indirect costs of obesity: a review of the current literature. Obes Rev 2008;9:489-500.

38 Golinvaux NS, Bohl DD, Basques BA, Fu MC, Gardner EC, Grauer JN: Limitations of administrative databases in spine research: a study in obesity. Spine J 2014;14:2923-2928.

39 Martin BJ, Chen G, Graham M, Quan H: Coding of obesity in administrative hospital discharge abstract data: accuracy and impact for future research studies. BMC Health Serv Res 2014;14:70.

40 Evans C, Crawford B: Patient self-reports in pharmacoeconomic studies. Their use and impact on study validity. Pharmacoeconomics 1999;15:241-256.

41 Cawley J, Meyerhoefer C: The medical care costs of obesity: an instrumental variables approach. J Health Econ 2012;31:219-230. 